\title{
Breast cancer advocacy: Changing perceptions
}

\author{
Ksenia P Koon, MS,, (I) Tanya Soldak, MD, (2) Julie R Gralow, MD, (1)
}

\begin{abstract}
Koon KP, Soldak T, Gralow JR. Breast cancer advocacy: Changing perceptions. Salud Publica Mex 2009;5I suppl 2:S323-S328.
\end{abstract}

\begin{abstract}
Breast cancer is a significant health burden worldwide. In the United States, the Breast Cancer Advocacy Movement has increased awareness, enhanced dialogue, and provided significant funding opportunities that previously did not exist. Various advocacy programs are beginning to emerge in developing countries in response to the increasing impact breast cancer is having in these regions of the world. This paper discusses the influence of the Breast Cancer Advocacy Movement in the US and proposes a format for working in conjunction with medical experts, political leaders and patient advocates to stimulate discussion and encourage sustainable outcomes in breast cancer internationally.
\end{abstract}

Key words: breast neoplasms; patient advocacy; world health; United States
Koon KP, Soldak T, Gralow JR.

Abogacía y cáncer de mama: el cambio en las percepciones.

Salud Publica Mex 2009;5 I supl 2:S323-S328.

\section{Resumen}

El cáncer de mama es una carga significativa de salud en el mundo. En Estados Unidos, el Movimiento deAbogacía para el Control del Cáncer de Mama ha hecho conciencia, mejorado el diálogo y provisto de oportunidades de financiamiento antes inexistentes. En los países en desarrollo, están emergiendo programas para el combate del cáncer de mama en respuesta al impacto creciente de la enfermedad en estas regiones. Este artículo aborda la influencia del movimiento en Estados Unidos y propone un formato para trabajar en conjunto con expertos en medicina, líderes políticos y defensores de pacientes y estimular la discusión y promoción de resultados sostenibles internacionalmente en cuanto al cáncer de mama.

Palabras clave: neoplasias de la mama; defensa del paciente; salud mundial; Estados Unidos
$I^{n}$ n the United States, breast cancer is the most fre1 quently diagnosed cancer in women and is the second leading cause of cancer-related female deaths. It is expected that 182,460 new female cases will be diagnosed in 2008 with a total of 40,480 female deaths attributable to breast cancer. ${ }^{1}$ Additionally, worldwide every 3 minutes a woman is diagnosed with breast cancer. The
World Cancer Report from the World Health Organization $(\mathrm{WHO})$ suggests that cancer rates are set to increase globally at an alarming rate over the next decade. ${ }^{2}$ Breast cancer is by far the most common cancer of women worldwide, comprising $23 \%$ of the estimated annual 4.7 million female cancer diagnoses. There were an estimated 1.15 million new breast cancer cases diagnosed

(I) Seattle Cancer Care Alliance, Seattle,WA.

(2) Resource and Policy Exchange, Inc, Belarus. 
across the globe in 2002 and there were an estimated 4.4 million women alive in whom breast cancer was diagnosed within the previous 5 years. ${ }^{3}$ Because of the challenges in detection and treatment, the majority of breast cancer-related deaths occur in low- and middleincome countries. ${ }^{4}$ Inarguably, breast cancer in women is a major international health burden.

Although the statistics for breast cancer worldwide seem high, the numbers in the United States represent improvements from the preceding decades; improvements that would not have been possible without the Breast Cancer Advocacy Movement. As early as 1913, efforts to publicize breast cancer were already underway in the United States when physicians and laypeople concerned with the high rates of cancer mortality formed a voluntary association, the American Society for the Control of Cancer. By the 1950s, the organization had become known as the American Cancer Society and it promoted breast self-exams as a way to detect cancers at an early stage. ${ }^{5}$ However, even by the 1960s, breast cancer in the United States was still largely viewed as a private, even shameful, experience that individual women were left to cope with themselves. ${ }^{6}$

The perception of breast cancer as a topic to be kept private slowly began to shift in the 1970s when prominent women spoke openly and candidly, as breast cancer advocates, about their own experiences with breast cancer. Fueled by the Women's Rights Movement and the Civil Rights Movement, vocalization began to spread. Specifically, in 1974, First Lady Betty Ford began speaking about her experience with breast cancer, which prompted many other notable figures to openly share their experiences. ${ }^{7}$ It is this public discourse that began to remove part of the stigma associated with breast cancer. Then, in 1975, a breast cancer patient named Rose Kushner, educating herself using medical literature, challenged physicians by advocating for a two-step mastectomy process (prior to this time, most physicians would perform a biopsy and mastectomy in a one-step process, leaving women little control over their treatment.) Rose Kushner not only declined the one-step process, thus forcing her surgeon to perform the biopsy and then discuss the option of mastectomy with her as a separate procedure, but she also declined the traditional radical mastectomy in favor of a modified mastectomy. During her recovery, Rose Kushner created the Breast Cancer Advisory Center in an attempt to educate women that they had options beyond what tradition dictated..$^{8}$ By 1979, Rose Kushner's influence was seen at the National Institutes of Health conference on breast cancer treatment, where a consensus panel concluded that radical mastectomy was no longer the one and only appropriate surgical treatment option.
Through her voice as a patient advocate, Rose Kushner was able to convince the panel to reject the one-step procedure, separating biopsy from operation and thereby empowering women to approach their own health care in an unprecedented manner. In this way, she gave credence to questioning the status quo and inspired many women to work with their physicians to make informed treatment decisions. ${ }^{8}$

In parallel with the HIV / AIDS Movement in the 1980s and 1990s, the Breast Cancer Advocacy Movement in the United States continued to take shape. In the mid1980s, the media helped establish the public perception of breast cancer as a prominent health problem in the United States. ${ }^{6}$ Also during this time, several private foundations were created and raised money toward breast cancer education and research. In the early 1990s, the women's cancer movement became increasingly visible and difficult for policy makers to ignore. During this time, "breast cancer activists attempt[ed] to broaden medicine's focus on disease by repeatedly stressing the economic, social, emotional, spiritual, and political consequences of breast cancer". ${ }^{9}$ Cancer advocates employed six strategies to influence health and social policy: 1) advocates empowered people to gain control of their health, 2) advocates established the words and phrases associated with the disease (e.g. "breast cancer survivors" rather than "breast cancer victims"), 3) advocates shaped research and federal drug approval agendas, 4) advocates directly lobbied officials, 5) advocates helped establish alternative clinic and preventative services for patients, and 6) advocates effected changes in laws and enforcements, including obtaining federally mandated funding for additional research and advocacy/educational programs. ${ }^{10}$ Activists also pressed scientists to include cancer advocates in program planning. As a result, many scientists feel that medicine has significantly benefited from the involvement of cancer advocates, and some scientists regularly request that advocates be included in the review process of their research projects. ${ }^{11}$

\section{Discussion}

The success of the Breast Cancer Advocacy Movement in the United States has helped raise worldwide awareness about the emerging cancer crisis. As with any successful movement, previously silent individuals gain the confidence needed to speak up and speak out about a topic for which they passionately support. As a result, society as a whole slowly begins to change its value system and what was once a secretive disease for an individual to bear alone becomes an open experience shared by an entire family and even an entire community. 
Part of the success of the Breast Cancer Advocacy Movement in the United States stemmed from the specificity of its programs to American culture. This is imperative to keep in mind for other breast cancer movements to be successful in different regions of the world, as each region is different and as such each will have different priorities necessary for a successful advocacy movement.

The Board on Global Health (BGH) of the Institute of Medicine of the National Academies (which collaborates with the medical academies in other countries, developed and developing, on health issues of mutual concern) emphasizes that it is essential to recognize the different situations that exist for each specific cultural region such that advocacy should be tailored to what is appropriate locally. The BGH further warns that "regardless of the services available and the attention paid to cancer, there is always more to be done locally by advocates without expanding beyond national borders...what is less common, and clearly more difficult, is to help to build advocacy where no leaders have yet emerged". 12

Based on historical experience in developed countries such as the United States and the countries of Western Europe, breast cancer advocacy movements tend to follow a certain developmental pattern. This pattern is not strictly linear, but in its general outline, it provides a basis for viewing advocacy programs in developing countries. Basically, the development of advocacy movements starts from a culturally determined wall of silence based on fear, misunderstanding, cultural practice, sexual taboo, and medical tradition. Once the silence is broken, new understandings emerge from increased dialog between patient and practitioner, medical institutions and governmental leaders, and nongovernmental organizations (NGOs) and international advocacy groups.

Although the political and societal specifics vary dramatically between countries, the impact that the Breast Cancer Advocacy Movement has had in the United States can serve as an example for mobilization between the public and private sectors on an emerging public health issue. The challenge that remains is how to successfully implement programs in different regions of the world.

Over the past several years, the breast program at the Seattle Cancer Care Alliance (with support from Susan G. Komen for the Cure), has facilitated culturally appropriate interchanges by bringing pertinent parties to the table to begin dialog on breast cancer advocacy issues specific to certain regions of the world. Each country, and every region within countries, then develops their own approaches to address these challenges based on their unique medical capacities, institutional resources, current political atmosphere and cultural constraints. Since 2003, we have facilitated biennial Breast Cancer Advocacy Conferences (specifically in Lithuania, Ukraine, and Belarus) to help foster and support the emerging breast cancer advocacy movements in Eastern Europe and Central Asia.

Increasing trends of breast cancer mortality have been observed in European countries since the 1950s. It is estimated that in 2002, the age standardized incidence of breast cancer in Eastern European women was 42.5 per 100,000 and the age-standardized mortality was 17.9 per $100,000 .^{3}$ These trends remained in 2006 (most current data), leaving breast cancer as the most common form of cancer diagnosed in European women. ${ }^{13}$

After the dissolution of the Soviet Union, Eastern Europe and Central Asia became regions with economic, social, and medical programs in a state of transition. Connections and resource sharing with robust systems, such as those in Russia, were lost and became increasingly unreliable. In a region where less than 20 years ago authoritarian rulers barred volunteer movements as unlawful interference with government policy, recent democracy building programs and positive political changes have transformed the landscape of civic society. In this new landscape, NGOs that were prohibited in the Soviet Union (prior to its collapse in 1991) have now sprung up to address gaps in virtually every category of public services.

In the healthcare sector, transitional governments with limited financial and technical resources have come to view the private and nonprofit sectors as viable partners in healthcare planning and delivery, incorporating the input and resources of local NGOs, including advocates, in nationwide healthcare programs. The first of these NGO and advocacy groups entered the Eastern Europe scene in the early 1990s in response to the 1986 nuclear accident at Chernobyl, Ukraine, and demonstrated links between this horrific accident and the subsequent rise in childhood cancers. These organizations received international support, demonstrated strong national influence, and ultimately changed children's cancer treatment outcomes in Eastern Europe. Breast cancer activists would eventually follow the path set by these groups, leveraging international and interregional cooperation to become the second largest group of patient advocates in Eastern Europe.

The relatively recent efforts of breast cancer advocacy groups of Eastern Europe and Central Asia have proven to be a very unique and powerful force in the region, capturing more attention and respect from regional policymakers and healthcare providers than anyone thought possible just 15 years ago. Breast 
cancer advocacy groups have utilized their influence to deliver feedback from patients to the highest government officials, facilitating policy level changes with the goal of ultimately reshaping public healthcare for millions of women in the region. While the growth of breast cancer advocacy groups has been rapid in some countries of the region, the concept of advocacy has not yet launched in others. Studying the disparity in these growth rates reveals useful findings that can be helpful in understanding other regions of the world as well.

To be certain, advocacy groups and other community-based organizations of Eastern Europe have come a long way in a very short time. However, there is still much progress to be made and there is a strong need for the governments to maintain their partnerships with NGOs and other advocacy organizations at a local level to ensure the successful implantation of breast cancer programs. Given the ongoing social unrest in this region of the world, breast cancer advocacy groups have the ability to dramatically impact women's healthcare in the post-communist and socialist republics of Eastern Europe and Central Asia than perhaps anywhere else in the world.

Advocates and NGOs in some countries of Eastern Europe have benefited immensely from their government's progressive international relations. The European Cancer Patient Coalition, the International Union Against Cancer (UICC), and Reach to Recovery have all provided direct assistance to help organizations in new members of the European Union for raising standards in breast cancer care and treatment. In Eastern Europe countries formerly part of the USSR, a widely shared language (Russian) and political history (Soviet Union, Communism, Socialism) have enabled NGOs and other advocates from neighboring countries to work closely with one another, sharing resources to address commonly held concerns. Cross border collaboration and leveraging of shared traits between neighboring nations is an effective method for countries with limited resources to raise their capacities to respond to breast cancer issues.

Given these developing social and political parameters and the obvious need to enhance dialogue, the Seattle Cancer Care Alliance breast program's Breast Cancer Advocacy Conferences (held in 2003, 2005, and 2007) have worked to attract public attention in the region. We have supplied a platform that allows the voice of patients and advocates to be heard alongside medical professionals and policy makers. These programs have expanded the powerful concept of "advocacy" to many regional activists, providing evidence-based information on breast cancer and raising awareness on the need and potential for community led efforts. Our programs provide a forum for advocates to discuss challenges and achievements relative to their own region, thereby allowing the exchange of ideas on solutions to overcoming obstacles. This has the fortunate effect of empowering breast cancer advocates and survivors to take action in their own countries. These conferences have also been instrumental in connecting, sometimes for the first time, medical professionals and patient advocates from throughout the region; past conferences have had representatives from Ukraine, Russia, Belarus, Poland, Lithuania, Estonia, Romania, Moldova, Georgia, Kyrgyzstan, Tajikistan, Uzbekistan, and Kazakhstan. The roundtable discussions have focused on some of the most important medical and emotional topics surrounding breast cancer specific to this part of the world. Discussion topics have included the Chernobyl disaster, relationships with pharmaceutical companies, making advances with limited resources, obtaining financial support, and overcoming emotional and physical obstacles in diagnosis. As was seen during the initiation of the breast cancer advocacy movement in the United States, patients become more willing to publicly acknowledge their fight with breast cancer and subsequently begin to see how they too can play important roles in furthering public education and influencing public policy. In addition, the connections that have been initiated by these programs have opened up opportunities for collaboration that otherwise would not have existed.

Perhaps most importantly, these programs have served as a catalyst for launching subsequent breast cancer advocacy initiatives throughout this region. We have seen that the conferences themselves are just the starting point for helping advocates find their voice. As a result of the 2007 conference in Minsk, Belarus, an ancillary forum was organized specifically by Byelorussian breast cancer advocates. Local advocates tackled strategies for collectively creating and sustaining advocacy and education efforts in their own country. This gathering also represented the first time in this country's history when physicians sat down in the same room with patient advocates and exchanged perspectives in a public setting. This unique exchange allowed the opportunity for cancer survivors and medical professionals to address the issues surrounding breast cancer advocacy, screening, and treatment together. The participating groups have expressed appreciation for the opportunity to engage in a collaborative forum because the resulting unity has created a sense of empowerment that did not previously exist. In a country such as Belarus, where certain civil liberties are still suppressed, this in and of itself is a significant achievement that promises to have far reaching implications. 
Elsewhere in Eastern Europe, as recently as 1997 no breast support groups (or even the concept of patient support systems or services) existed in Ukraine. In the late 1990s, the United States Agency for International Development (USAID) funded a three-year Breast Cancer Assistance Project which was managed by an international health organization called the Program for Appropriate Technology in Health (PATH). Although the primary aim of the project was to strengthen breast cancer early detection, diagnosis and treatment in three cities in Ukraine, an additional key objective was to improve the quality of life of breast cancer patients. In order to accomplish this, the project educated breast cancer patients and encouraged the establishment of patient survivor groups. By 2001, advocates from 15 Ukrainian cities had begun providing mutual support in an organized way. ${ }^{14}$ That same year, an annual breast cancer Walk (the "March for Life and Hope") was organized by breast cancer advocates in Kyiv, Ukraine. ${ }^{15}$ The fact that the Walk generates enough interest and support to annually shut down the central thoroughfare in the Ukrainian capital speaks volumes. The success of the program provides one of the best examples of overcoming obstacles and the illustrates the full impact of advocates' voices. As an adjunct to our 2005 conference in Kiev, Ukraine, these same breast cancer advocates from around the country arranged an breast cancer support group conference, which included representation from 22 of the 25 regions (or oblasts) of Ukraine; an amazing feat considering that less than a decade earlier no breast cancer support existed in Ukraine. ${ }^{16}$ The Ukrainian advocacy conference (2005), as well as the annual Walk in Kyiv, represent elements of a movement that has already improved the lives of hundreds of women with breast cancer in the region.

The breast cancer advocacy and outreach endeavors of the Seattle Cancer Care Alliance's breast program have provided unique forums for the exchange of ideas and perspectives in a climate where restricted funds and a history of limited social and political acceptance have made breast cancer outreach a challenging undertaking. Advocates, physicians, and health policy makers alike have provided feedback indicating that these exchanges provide an effective way to promote progress and increase dialogue in regions of the world where breast cancer advocacy movements are still taking shape. Our group plans to continue to promote the exchange of ideas and increase channels of communication to create sustainable improvements in breast cancer prevention, screening, treatment, education, and survivorship throughout developing countries around the world.

\section{Conclusion}

Breast cancer is increasingly becoming an international crisis. The good news is that there is evidence to suggest that a healthy lifestyle and public health actions can curb the increase in cancer incidence, and together they have the potential to prevent approximately one-third of cancers worldwide. ${ }^{2}$ In developing countries, the challenge centers around not only on how to implement successful and appropriate collaborative programs, but also on how to give advocacy a voice given that each country and region has its own unique culture and priorities. The programs that worked in the United States targeted the sensibilities and culture at a local level and, consequently, will not necessarily be the same programs that will work in other regions of the world. Therefore, it is important that NGOs and advocates create programs that are meaningful to the local communities being targeted. Tailoring specific programs to fit the needs of patients and advocates in this way can have the same effect that Rose Kushner had on the breast cancer advocacy movement in the United States; advocates can, in fact, change the face of medicine. After all, when spoken together, a few lone voices sound like a shout, and a shout is difficult to ignore.

\section{Acknowledgements}

We would like to thank Amy Myers, MPH for all of her assistance.

\section{References}

I. Jemal A, Siegel R, Ward E, Hao Y, Xu J, Murray T, et al. Cancer statistics, 2008. CA Cancer J Clin 2008;58:71-96.

2. World Health Organization. Global cancer rates could increase by $50 \%$ to 15 million by 2020 . Available at: http://www.who.int/mediacentre/news/ releases/2003/pr27/en/.Accessed on October 28, 2008.

3. Parkin D, Bray F, Ferlay J, Pisani P. Global cancer statistics, 2002. CA Cancer J Clin 2005;55:74-108.

4. Porter P."Westernizing" women's risk? Breast cancer in lower-income countries. NEJM 2008;358:213-216.

5. Lerner B. Breast cancer activism: past lessons, future directions. Nat Rev 2002;2:225-230.

6. Kolker E. Framing as a culture resource in health social movements: funding activistm and the breast cancer movement in the US 1990-1993. Sociol Health Illn 2004;26(6):820-844.

7. Riter B. A very brief history of the breast cancer advocacy movement. Available at: http://www.cancerlynx.com/breastadvocacy.html. Accessed on December 2, 2008.

8. Lerner B. No shrinking violet: Rose Kushner and the rise of American breast cancer activism. WJM 200 I; I74:362-365. 
9. Myhre J.The breast cancer movement: seeing beyond consumer activism. JAMWA 1999;54(I):29-3I.

10. Keefe R, Lane S, Swarts H. From the bottom up: tracing the impact of four health-based social movements on health and social policies. J Health Soc Policy 2006;2I(3):55-69.

II. Collyar D. How have patient advocates in the United States benefited cancer research? Nat Rev 2005;5:73-78.

12. Institute of Medicine (US). Cancer control opportunities in low and middle-income countries. Sloan F, Gelband H, eds. Committee on Cancer Control in Low- and Middle-Income Countries. Board on Global Health, Washington DC: National Academies Press, 2007.

13. Ferlay J,Autier P, Boniol M, Heanue M, Colombert M, Boyle P. Estimates of the cancer incidence and mortality in Europe in 2006. Ann Oncol 2007;18:581-592.
14. Bishop A, Kovtun A, Okromeshko S, Karpilovskaya S, Suprun N Lives renewed: the emergence of a breast cancer survivor movement in Ukraine. Reprod Health Matters 2001;9(18):126-134.

15. PATH. Improving health care for women with breast cancer. Available at: http://www.path.org/projects/ukraine_breast_cancer_project.php. Accessed on October 28, 2008.

16. All-Ukrainian Public Organization. Together against cancer.Available at: http://amazonki.kiev.ua/pro_obednannja_razom_proti_eng.html.Accessed on October 28, 2008. 